\title{
Article \\ The Green Synthesis of 2D Copper Nanosheets and Their Light Absorption
}

\author{
Suhyun Lee, Suming Wang, Chien Wern (D) and Sung Yi * \\ Department of Mechanical and Materials Engineering, Portland State University, Portland, OR 97207-075, USA; \\ suhyun@pdx.edu (S.L.); wangsuming1993@gmail.com (S.W.); wernc@pdx.edu (C.W.) \\ * Correspondence: syi@pdx.edu
}

check for

updates

Citation: Lee, S.; Wang, S.; Wern, C.; Yi, S. The Green Synthesis of 2D

Copper Nanosheets and Their Light Absorption. Materials 2021, 14, 1926. https://doi.org/10.3390/ma14081926

Academic Editor: George Kioseoglou

Received: 22 January 2021

Accepted: 27 March 2021

Published: 12 April 2021

Publisher's Note: MDPI stays neutral with regard to jurisdictional claims in published maps and institutional affiliations.

Copyright: (c) 2021 by the authors. Licensee MDPI, Basel, Switzerland. This article is an open access article distributed under the terms and conditions of the Creative Commons Attribution (CC BY) license (https:// creativecommons.org/licenses/by/ $4.0 /)$.

\begin{abstract}
In this study, a new green synthesis method for two-dimensional (2D) copper nanosheets is developed using methylsulfonylmethane $\left(\mathrm{DMSO}_{2}\right)$. The chemical composition and light absorption of $2 \mathrm{D}$ copper nanosheets are also studied. A new green method is mainly to utilize $\mathrm{DMSO}_{2}$, which is environmentally friendly enough to be considered a food-grade chemical, unlike the conventional method using toxic chemicals, such as ammonia and hydrazine $\left(\mathrm{N}_{2} \mathrm{H}_{4}\right)$. With a reducing agent, the aggregation of uncertain copper products was produced in the absence of $\mathrm{DMSO}_{2}$, while $2 \mathrm{D}$ copper nanosheets were formed in the presence of $\mathrm{DMSO}_{2}$. The optimum concentration of $\mathrm{DMSO}_{2}$ as a surfactant was determined to be $2 \mathrm{M}$, resulting in large surface areas with regular edges. FTIR spectrum confirmed C-H bonding from $\mathrm{DMSO}_{2}$ used to synthesize $2 \mathrm{D}$ copper nanosheets. The light absorption peak was revealed at $800 \mathrm{~nm}$ in the UV-vis spectrum. This proposed new green method not only has a simpler process than the conventional methods, such as hydrothermal method and chemical bath deposition, but also substitutes toxic chemicals with $\mathrm{DMSO}_{2}$. 2D copper nanosheets can be used for various applications, including conductive filler or ink in the flexible electronics and laser photonics fields.
\end{abstract}

Keywords: synthesis; 2D nanomaterial; nanosheets; 2D copper nanosheets

\section{Introduction}

Metal nanomaterials have attracted interest due to their great transmittance and electrical, thermal, mechanical, and catalyst properties. They enable extensive applications in nanoscience and nanotechnology, such as flexible electronics [1]. In particular, twodimensional (2D) nanomaterials have unconventional exposed surface properties indicating high electron mobility and good thermal conductivity [2-5]. Besides, 2D nanomaterials can provide ideal morphology for vigorous electrocatalysts because the pathways of ion and electron diffusion are significantly shortened, and electrochemically active sites are large $[6,7]$.

2D nanosheets are a promising nanomaterial due to their thickness of nanometers along with in-plane lattice and pores between interlayers. 2D nanosheets offer minimized transport resistance and maximized selectivity depending on molecular size [8]. Single-layer manganese dioxide $\left(\mathrm{MnO}_{2}\right)$ nanosheets and $\mathrm{ZnMn}_{2} \mathrm{O}_{4}$-graphene ( $\left.\mathrm{ZMO}-\mathrm{G}\right)$ nanosheets demonstrated attractive electrochemical properties, such as high capacitance, and better rate performance for electrical energy storage system [9-11]. Furthermore, graphene and graphene oxide nanosheets were investigated in energy-related areas, water desalination, and filtration as functional separation membranes [8,12]. 2D copper oxide $(\mathrm{CuO})$ nanosheet electrode film was found to be a low-cost catalyst material with great catalytic activity for electrochemical water splitting into hydrogen and oxygen [6]. Copper $\mathrm{Cu}$ ) nanosheet ink presented stable conductive performance and could be used directly on flexible electronic circuits [13].

The synthesis methods of 2D metal nanomaterials are largely categorized into two methods, namely top-down and bottom-up methods. Top-down methods are mainly 
employed for producing layered bulk material, while bottom-up methods are widely utilized in practical applications [14]. 2D metal nanosheets are dominatingly synthesized through bottom-up methods due to the advantage of practical application [15]. Among bottom-up methods, hydrothermal and solvothermal methods are used to synthesize metal 2D nanosheets.

Dang et al. (2014) and Dehghanpour et al. (2015) employed the hydrothermal method to produce $\mathrm{Cu}$ nanosheets using polyvinylpyrrolidone (PVP) and cetyltrimethylammonium bromide (CTAB), respectively, as surface capping agent $[13,16]$. Hou et al. (2013) and Duan et al. (2014) presented the synthesis of rhodium (Rh) nanosheets by the solvothermal method in the presence of surfactants and the absence of surfactants, respectively $[17,18]$. Besides these methods, Hu et al. (2010) prepared metal oxide nanosheets using several metals (e.g., $\mathrm{Mn}, \mathrm{Co}, \mathrm{Fe}$, and $\mathrm{Ni}$ ) by refluxing metal salt in absence of any surfactants, or templates [19]. Dubal et al. (2010) and Pawar et al. (2017) synthesized CuO nanosheets using ammonia as a reducing agent through chemical bath deposition $[6,20]$. Shaik et al. (2016) demonstrated the synthesis of $\mathrm{Cu}$ nanosheets through the reduction of copper salts at room temperature in the presence of CTAB as a surfactant and hydrazine $\left(\mathrm{N}_{2} \mathrm{H}_{4}\right)$ as a reducing agent [21]. The foregoing methods require complicated processes, high temperature, and prolonged reaction time.

In recent years, significant attention has been given to various $2 \mathrm{D}$ metal nanomaterials such as manganese $(\mathrm{Mn})$, cobalt $(\mathrm{Co})$, nickel $(\mathrm{Ni})$, and rhodium $(\mathrm{Rh})[17,22-24]$. However, one of the important nanomaterials is copper due to its high conductivity, low cost, high abundance, and even flexibility in the form of nanowires. Furthermore, 2D copper nanosheets demonstrated higher conductivity and lower resistivity than copper nanowires or mixed products of copper nanowires and 2D nanosheets [25]. Copper-based nanomaterials have been presented in many applications such as electrocatalysts for water oxidation [26], photodetectors [27], conductive ink [13], supercapacitors [20], and conductive fillers [25]. Therefore, 2D copper nanosheets are considered promising nanomaterials for the substitution of novel metal nanomaterials. However, the sources for the synthesis of 2D copper nanosheets are scarce. In addition, the synthesis methods of 2D copper nanosheets require toxic chemicals, such as ammonia and $\mathrm{N}_{2} \mathrm{H}_{4}$, and are implemented with complicated procedures $[6,20,21]$.

In this present study, a new green method to synthesize $2 \mathrm{D}$ copper nanosheets is developed using methylsulfonylmethane $\left(\mathrm{DMSO}_{2}\right)$, which has not been reported before for the synthesis of nanomaterials. $\mathrm{DMSO}_{2}$ is environmentally friendly enough to be used as a food-grade chemical and can be used to substitute the toxic chemicals, such as ammonia and $\mathrm{N}_{2} \mathrm{H}_{4}$, used in the conventional method. In addition, two reducing agents, namely sodium hydroxide $(\mathrm{NaOH})$ and lithium hydroxide $(\mathrm{LiOH})$, are employed. 2D copper nanosheets are characterized by transmission electron microscopy (TEM), energydispersive X-ray spectroscopy (EDX), Fourier transform infrared spectroscopy (FTIR), and ultraviolet-visible spectroscopy (UV-Vis).

\section{Materials and Methods}

\subsection{Materials}

For the synthesis of $2 \mathrm{D}$ copper nanosheets, copper sulfate $\left(\mathrm{CuSO}_{4}\right)$ was utilized as the copper precursor. Sodium hydroxide $(\mathrm{NaOH})$ and lithium hydroxide $(\mathrm{LiOH})$ were used as reducing agents to reduce copper ions in the solution. Methylsulfonylmethane $\left(\mathrm{DMSO}_{2},>99.8 \%\right.$, Bergstrom Nutrition, Vancouver, WA, USA) was employed to determine whether it plays the role of a surfactant in the synthesis process. Deionized water $\left(\mathrm{DI} \mathrm{H}_{2} \mathrm{O}\right)$ was used to dissolve all the chemicals.

\subsection{Method}

2D copper nanosheets were synthesized by a new green method. In order to keep constant reaction temperature for $2 \mathrm{~h}$ reaction time, the synthesis was carried out by placing an Erlenmeyer flask containing material solution into the water bath. In addition, 
all steps were implemented under magnetic stirring at $300 \mathrm{rpm}$ to keep the solution in a homogeneous state. First, 1, 2, or $3 \mathrm{M}$ of methylsulfonylmethane $\left(\mathrm{DMSO}_{2}\right), 0.01 \mathrm{M}$ of copper sulfate $\left(\mathrm{CuSO}_{4}\right)$, and $0.3 \mathrm{M}$ of reducing agents were dissolved with deionized water (DI $\mathrm{H}_{2} \mathrm{O}$ ) in each Erlenmeyer flask, separately. $\mathrm{CuSO}_{4}$ solution was added to $\mathrm{DMSO}_{2}$ solution $(1,2$, or $3 \mathrm{M})$ under magnetic stirring for $10 \mathrm{~min}$, and then $0.05 \mathrm{~mL}$ of $0.3 \mathrm{M}$ sodium hydroxide $(\mathrm{NaOH})$ reducing agent was added. This solution in an Erlenmeyer flask was stirred for $30 \mathrm{~min}$ at a water-bath temperature of $80^{\circ} \mathrm{C}$. When using a lithium hydroxide $(\mathrm{LiOH})$ reducing agent instead of $\mathrm{NaOH}$, the process of synthesis and concentration of materials was kept the same. After $30 \mathrm{~min}$, the solution was washed with methanol to remove impurities of chemicals and dried in a vacuum desiccator at room temperature under full vacuum for at least $2 \mathrm{~h}$.

\subsection{Characterization}

The morphology and arrangement of 2D copper nanosheets were investigated by transmission electron microscopy (TEM, Tecnai F-20, FEI, Hillsboro, OR, USA) with $200 \mathrm{kV}$ accelerating voltage, and energy-dispersive X-ray spectroscopy (EDX) was employed for elemental analysis of 2D copper nanosheets. To analyze the composition of 2D copper nanosheets, Fourier transform infrared spectroscopy (FTIR, Thermo Fisher, Hillsboro, OR, USA) was used. The light absorption spectrum of 2D copper nanosheets was obtained by ultraviolet-visible spectroscopy (UV-Vis, Evolution 260 BIO, Thermo Fisher, Hillsboro, OR, USA).

\section{Results and Discussion}

\subsection{The Formation of 2D Copper Nanosheets}

2D copper nanosheets were synthesized by adding methylsulfonylmethane $\left(\mathrm{DMSO}_{2}\right)$, copper sulfate $\left(\mathrm{CuSO}_{4}\right)$, and sodium hydroxide $(\mathrm{NaOH})$ together. As shown in Figure 1, 2D copper nanosheets were formed under various conditions. Figure 1a,b show 2D copper nanosheets synthesized without $\mathrm{NaOH}$ reducing agent and $\mathrm{DMSO}_{2}$, respectively. Figure $1 \mathrm{c}$ represents $2 \mathrm{D}$ copper nanosheets synthesized with $\mathrm{NaOH}$ reducing agent and $\mathrm{DMSO}_{2}$. The chemical reaction can be represented as follows:

$$
\begin{gathered}
\mathrm{CuSO}_{4}+2 \mathrm{NaOH} \rightarrow \mathrm{Cu}(\mathrm{OH})_{2}+\mathrm{Na}_{2} \mathrm{SO}_{4} \\
\mathrm{Cu}(\mathrm{OH})_{2}+\mathrm{NaOH} \rightarrow \mathrm{Na}_{2} \mathrm{CuO}_{2}^{-}+\mathrm{H}_{2} \mathrm{O}+\mathrm{H}^{+} \\
\mathrm{Na}_{2} \mathrm{CuO}_{2}^{-}+\mathrm{H}^{+} \rightarrow \mathrm{Cu}+2 \mathrm{NaOH}
\end{gathered}
$$

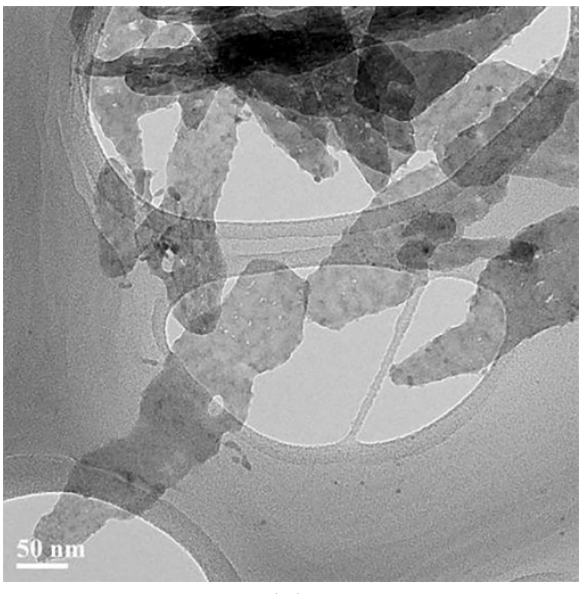

(a)

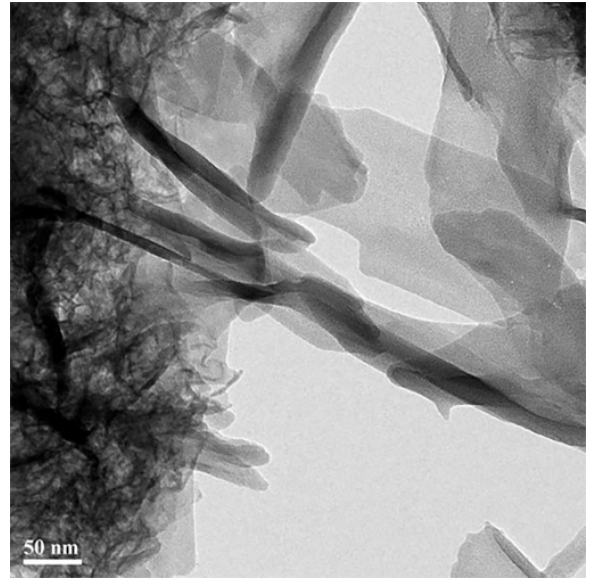

(b)

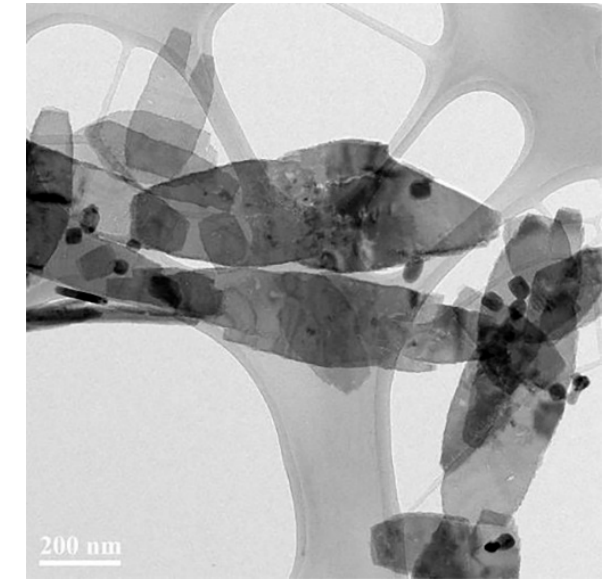

(c)

Figure 1. TEM images of $2 \mathrm{D}$ copper nanosheets: (a) without $\mathrm{NaOH}$ reducing agent; (b) without $\mathrm{DMSO}_{2} ;(\mathbf{c})$ with $\mathrm{NaOH}$ reducing agent and $\mathrm{DMSO}_{2}$. 
The surfaces of 2D copper nanosheets were $0.365 \mu \mathrm{m}$ in length and $0.1 \mu \mathrm{m}$ in width in the absence of a $\mathrm{NaOH}$ reducing agent, as shown in Figure 1a. These 2D copper nanosheets display irregular edges and some pores on the surface. This may result from an incomplete reduction process of copper ions due to the fast oxidation of $2 \mathrm{D}$ copper nanosheets. The $2 \mathrm{D}$ copper nanosheets produced without $\mathrm{DMSO}_{2}$ are shown in Figure $1 \mathrm{~b}$. A complete reduction process seems to have occurred, as the edges are regular and improved when compared to those shown in Figure 1a. However, the remarkable aggregation of the uncertain copper products makes it difficult to measure the length and width of these 2D copper nanosheets. This aggregation could be caused by the lack of surface energy due to the absence of surfactant in the solution. As shown in Figure 1c, 2D copper nanosheets synthesized with $\mathrm{NaOH}$ reducing agent and $\mathrm{DMSO}_{2}$ were $0.88 \mu \mathrm{m}$ in length and $0.32 \mu \mathrm{m}$ in width, revealing regular edges and larger surface areas when compared to those shown in Figure 1a. In addition, there is no aggregation of the uncertain copper products, unlike that seen in Figure 1b, even though some copper nanoparticles were formed simultaneously. This may be caused by a fast reduction reaction and nucleation rate because $\mathrm{NaOH}$ is a strong reducing agent.

$\mathrm{DMSO}_{2}$ may play a role as a copper surfactant in this process and be an important factor in forming $2 \mathrm{D}$ copper nanosheets of large surface areas with regular edges. This is because copper ions cannot have a driving force to grow desirable 2D nanosheets without copper surfactant. To synthesize 2D copper nanosheets of large surface areas with regular edges, the concentration of $\mathrm{DMSO}_{2}$ was controlled.

Figure 2 presents the 2D copper nanosheets synthesized with various concentrations of $\mathrm{DMSO}_{2}$. The 2D copper nanosheets synthesized with $1 \mathrm{M}$ of $\mathrm{DMSO}_{2}$ shown in Figure $2 \mathrm{a}$ reveal a length of $0.95 \mu \mathrm{m}$ and a width of $0.2 \mu \mathrm{m}$. These 2D copper nanosheets were irregularly synthesized, as indicated by the small surface areas and the aggregation of $2 \mathrm{D}$ copper nanosheets shown in Figure 2a. Besides, copper products in the form of nanorods and needles can be observed. When $2 \mathrm{M}$ of $\mathrm{DMSO}_{2}$ was added, $2 \mathrm{D}$ copper nanosheets $0.955 \mu \mathrm{m}$ in length and $0.42 \mu \mathrm{m}$ in width were found to have large surface areas with regular surface edges, as shown in Figure $2 b$. With further increase in the concentration of $\mathrm{DMSO}_{2}$, the yield of 2D copper nanosheets began to develop as shown in Figure 2c. However, these 2D copper nanosheets seem to be $0.4 \mu \mathrm{m}$ in length and less than $0.2 \mu \mathrm{m}$ in width with surface areas that are not as large as those of nanosheets synthesized with $2 \mathrm{M}$ of $\mathrm{DMSO}_{2}$. The irregular edges and aggregation of 2D copper nanosheets can be observed. Furthermore, Figure 2c shows that 2D copper nanosheets seem to form multiple layers, making it difficult for them to disperse.

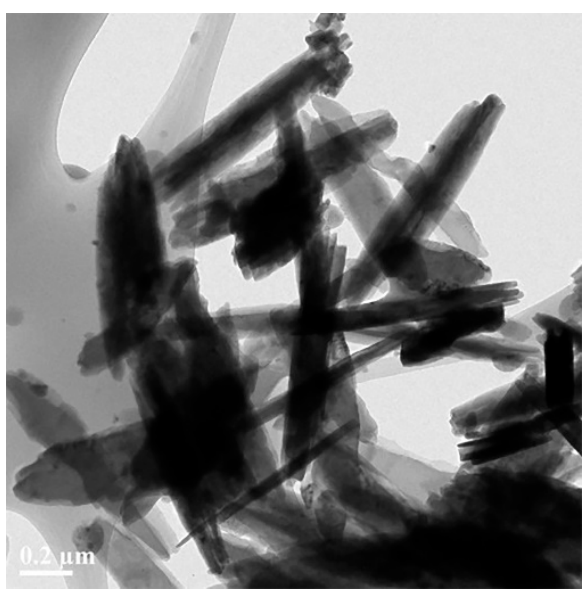

(a)

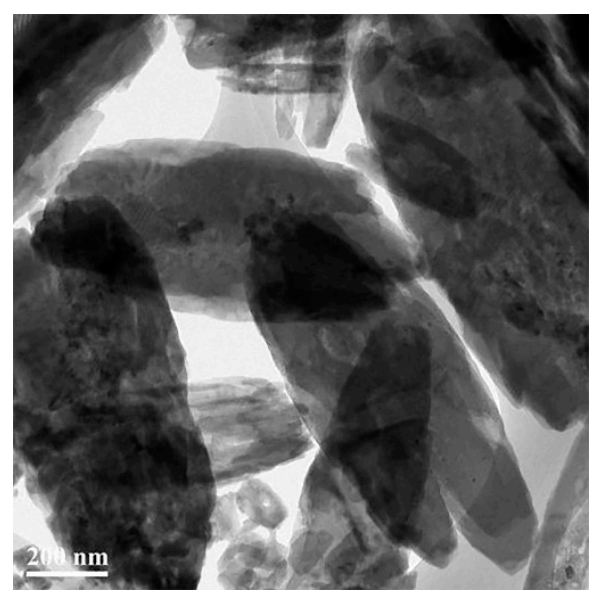

(b)

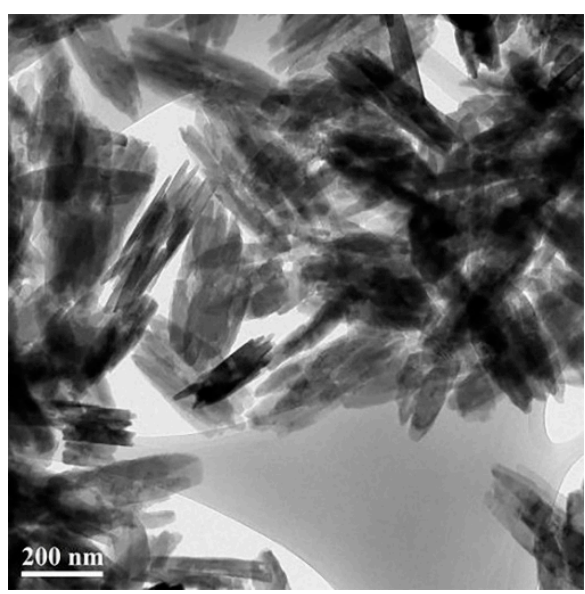

(c)

Figure 2. TEM images of 2D copper nanosheets: (a) $1 \mathrm{M}$; (b) $2 \mathrm{M}$; (c) $3 \mathrm{M}$ of $\mathrm{DMSO}_{2}$. 
The low concentration of $\mathrm{DMSO}_{2}$ is likely to cause high surface tension and low surface energy. This makes it difficult for the copper ions to form large areas. On the other hand, the high concentration of $\mathrm{DMSO}_{2}$ may cause low surface tension and high surface energy, making the copper ions actively react with each other. However, the excess amount of $\mathrm{DMSO}_{2}$ is likely to lead to fast crystallization that limits the growth of $2 \mathrm{D}$ copper nanosheets. Therefore, $\mathrm{DMSO}_{2}$ added at a sufficient concentration (i.e., $2 \mathrm{M}$ of $\mathrm{DMSO}_{2}$ in this study) could act as a surfactant in the synthesis process. $\mathrm{DMSO}_{2}$ is environmentally friendly enough to be used as a food-grade chemical. Thus, $\mathrm{DMSO}_{2}$ may be used as a substitute for the toxic chemicals, such as ammonia and $\mathrm{N}_{2} \mathrm{H}_{4}$, used in the conventional method.

Lithium hydroxide $(\mathrm{LiOH})$ is used as a weak reducing agent to prevent the generation of by-products of copper nanoparticles. The chemical reaction can be represented by the same mechanism as chemical reactions (1)-(3):

$$
\begin{gathered}
\mathrm{CuSO}_{4}+2 \mathrm{LiOH} \rightarrow \mathrm{Cu}(\mathrm{OH})_{2}+\mathrm{Li}_{2} \mathrm{SO}_{4} \\
\mathrm{Cu}(\mathrm{OH}) 2+\mathrm{LiOH} \rightarrow \mathrm{Li}_{2} \mathrm{CuO}_{2}^{-}+\mathrm{H}_{2} \mathrm{O}+\mathrm{H}^{+} \\
\mathrm{Li}_{2} \mathrm{CuO}_{2}{ }^{-}+\mathrm{H}^{+} \rightarrow \mathrm{Cu}+2 \mathrm{LiOH}
\end{gathered}
$$

Figure 3 shows the morphology of 2D copper nanosheets synthesized with $\mathrm{LiOH}$. These 2D copper nanosheets had a length greater than $1 \mu \mathrm{m}$ in and a width of $0.24-0.4 \mu \mathrm{m}$. The length of these 2D copper nanosheets was longer than that found when using $\mathrm{NaOH}$ as a reducing agent. However, the width of 2D copper nanosheets was formed randomly. In addition, aggregation of the small-sized 2D copper nanosheets that are difficult to measure in length and width was seen, as shown in Figure 3. However, 2D copper nanosheets were synthesized without the formation of copper nanoparticles as by-products, unlike when using a $\mathrm{NaOH}$ reducing agent. This is because $\mathrm{LiOH}$ is basically a weaker reducing agent than $\mathrm{NaOH}$ and could cause a slower reduction process. Therefore, $\mathrm{LiOH}$, as a reducing agent, can start to react with copper precursor without the formation of unnecessary product. However, the use of $\mathrm{LiOH}$ is likely to control the concentration of $\mathrm{DMSO}_{2}$ simultaneously in order to reduce the difference in the width of $2 \mathrm{D}$ copper nanosheets.

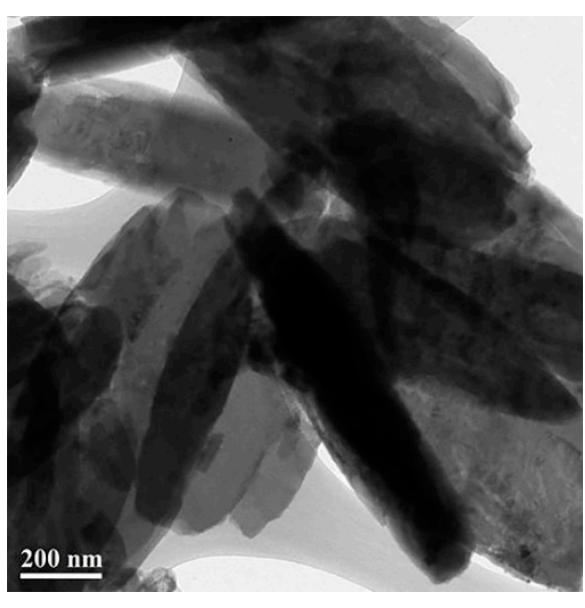

(a)

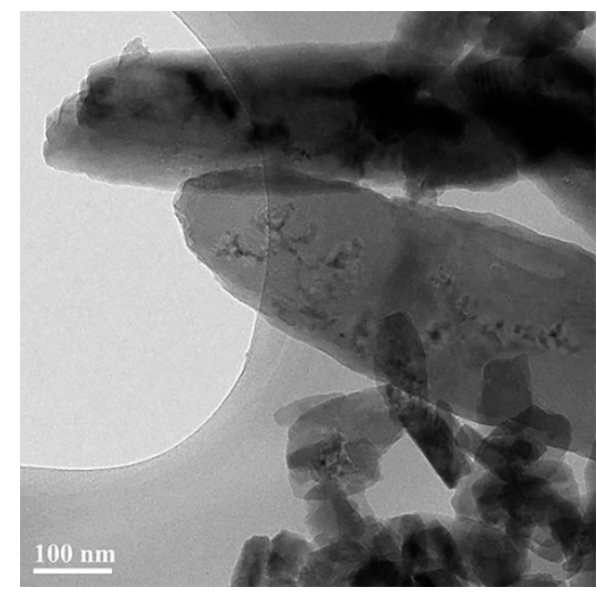

(b)

Figure 3. TEM images of $2 \mathrm{D}$ copper nanosheets synthesized with the $\mathrm{LiOH}$ reducing agent: the magnification of (a) $200 \mathrm{~nm}$; (b) $100 \mathrm{~nm}$.

Figure 4 shows the energy-dispersive X-ray spectroscopy (EDX) pattern of 2D copper nanosheets. The element analysis from the EDX spectrum was conducted for copper $(\mathrm{Cu})$ in 2D copper nanosheets. Some unexpected elements such as carbon (C) and oxygen (O) were revealed in the EDX spectrum, but with weak peaks. C detected from the TEM sample 
grid likely consisted of lacey carbon. O could be detected through the sealed thin window in the X-ray detector. It does not allow high counts, as shown in Figure 4. C and O peaks are not important for element analysis because the EDX spectrum results in the proportional weight percent. In Figure 4, a strong peak of $\mathrm{Cu}$ is observed at $8.04 \mathrm{keV}$, which means that the element of $\mathrm{Cu}$ is dominant in 2D copper nanosheets. Therefore, the formation of 2D copper nanosheets is confirmed by the presence of dominant $\mathrm{Cu}$.

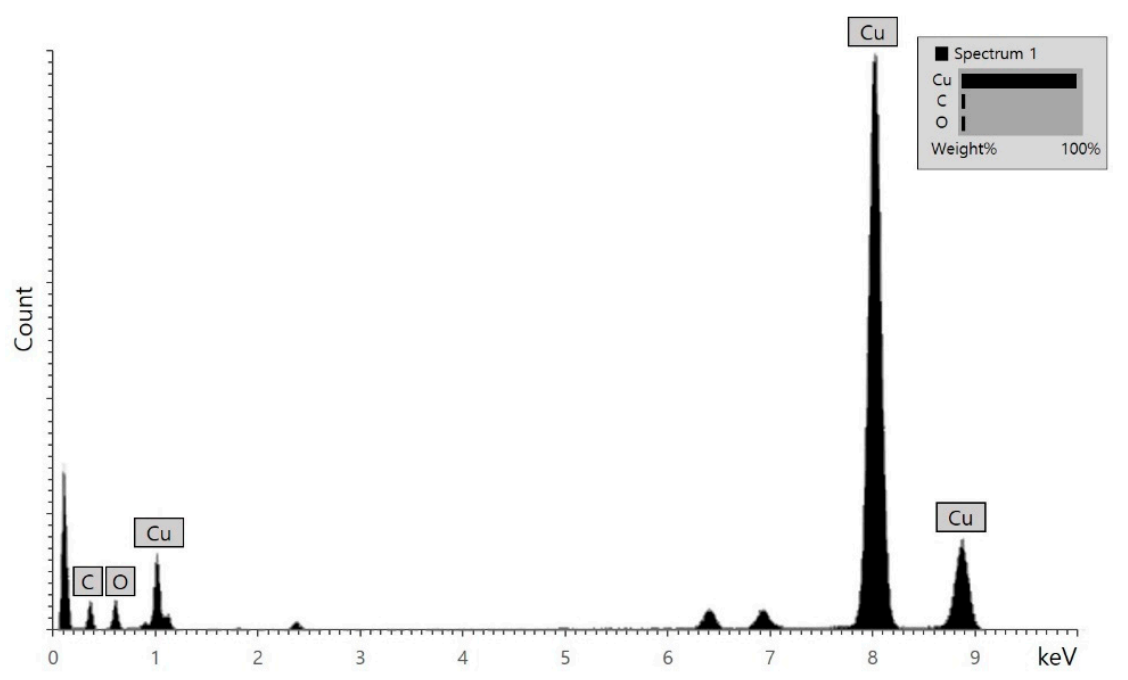

Figure 4. EDX spectrum of 2D copper nanosheets.

\subsection{FTIR Study}

Figure 5 displays the FTIR spectrum of 2D copper nanosheets produced with $\mathrm{LiOH}$. The region below $700 \mathrm{~cm}^{-1}$ has very small peaks that represent the vibration of $\mathrm{Cu}-\mathrm{O}$ stretching and bending. The peak around $1100 \mathrm{~cm}^{-1}$ may reveal $\mathrm{O}-\mathrm{H}$ bending vibration that is from either copper hydroxide $\left(\mathrm{Cu}(\mathrm{OH})_{2}\right)$ generated during the copper ion reduction process or a $\mathrm{LiOH}$ reducing agent [28]. Therefore, 2D copper nanosheets could be reduced by a $\mathrm{LiOH}$ reducing agent. The strong and sharp peak at $3138 \mathrm{~cm}^{-1}$ indicates $\mathrm{C}-\mathrm{H}$ bonding that is likely to be from the methyl group of $\mathrm{DMSO}_{2}$. Therefore, the successful use of $\mathrm{DMSO}_{2}$ to synthesize 2D copper nanosheets was confirmed by the observation of $\mathrm{C}-\mathrm{H}$ bonding. The FTIR spectrum in Figure 5 indicates the presence of some amount of water bound to the 2D copper nanosheet solution [11,20].

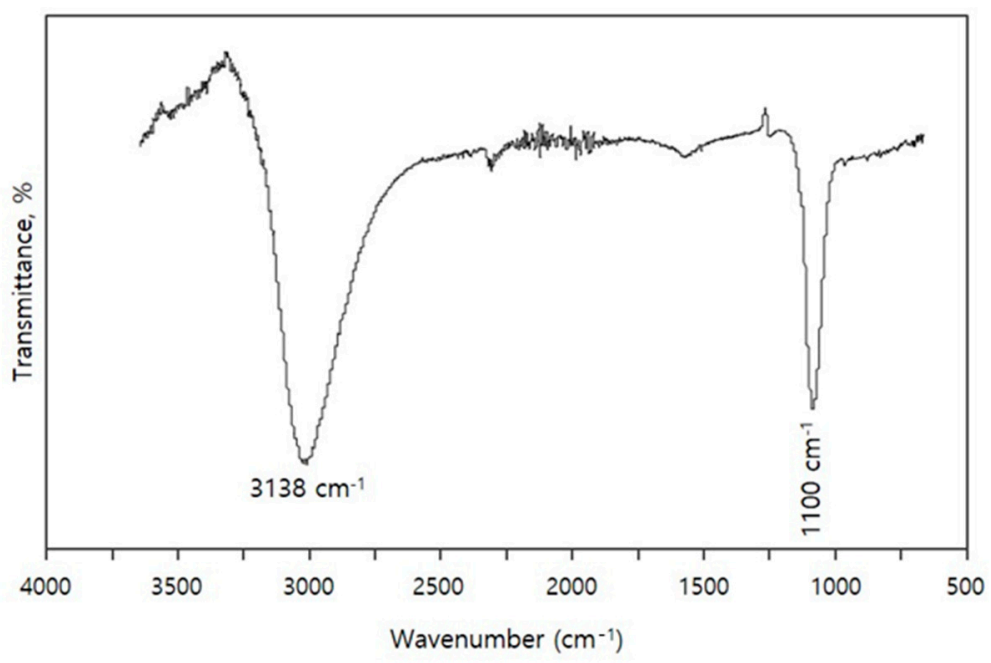

Figure 5. FTIR spectrum of 2D copper nanosheets synthesized with $\mathrm{LiOH}$. 


\subsection{UV-Vis Study}

Figure 6 shows the UV-Vis spectrum of 2D copper nanosheets prepared by adding $\mathrm{LiOH}$ as a reducing agent. As shown in Figure 6, the change in absorbance to a longer wavelength, i.e., the redshift, indicates that elongated 2D copper nanosheets were produced [21]. Besides, the large aspect ratio of 2D copper nanosheets has a large peak shift. A better absorbance ability indicates a larger aspect ratio. Therefore, 2D copper nanosheets produced are likely to have a large aspect ratio and high absorbance ability. As shown in Figure 6, the absorption peak of 2D copper nanosheets was around $800 \mathrm{~nm}$. 2D copper nanosheets can likely be used in laser photonic applications with a wavelength of $800 \mathrm{~nm}[29]$.

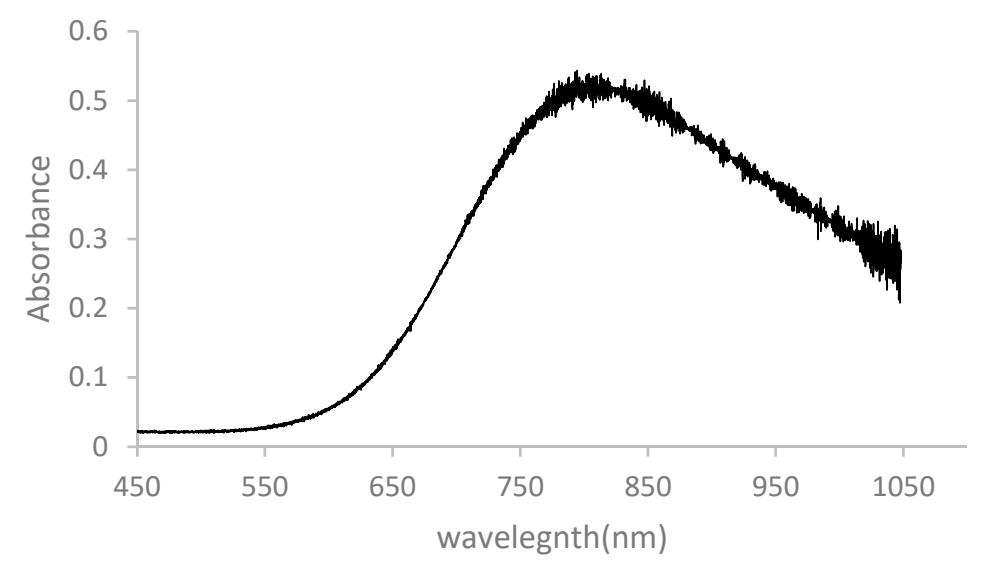

Figure 6. UV-Vis spectrum of 2D copper nanosheets synthesized with $\mathrm{LiOH}$.

\section{Conclusions}

In conclusion, a new green synthesis method of 2D copper nanosheets was successfully developed by using methylsulfonylmethane $\left(\mathrm{DMSO}_{2}\right)$, the use of which has not been reported before for the synthesis of nanomaterials. 2D copper nanosheets were formed in different morphologies with or without $\mathrm{NaOH}$ as a reducing agent and $\mathrm{DMSO}_{2}$ as a surfactant. With both $\mathrm{NaOH}$ and $\mathrm{DMSO}_{2}, 2 \mathrm{D}$ copper nanosheets of $0.88 \mu \mathrm{m}$ in length and $0.32 \mu \mathrm{m}$ in width were obtained without aggregation. The concentration of $\mathrm{DMSO}_{2}$ was crucial for the formation of 2D copper nanosheets of large surface areas with regular edges. $2 \mathrm{M}$ of $\mathrm{DMSO}_{2}$ was desirable for 2D copper nanosheets, resulting in $0.955 \mu \mathrm{m}$ length and $0.42 \mu \mathrm{m}$ width. The addition of $\mathrm{LiOH}$ instead of $\mathrm{NaOH}$ as a weak reducing agent and $\mathrm{DMSO}_{2}$ formed 2D copper nanosheets of $1 \mu \mathrm{m}$ in length and $0.24-0.4 \mu \mathrm{m}$ in width. Therefore, 2D copper nanosheets could be produced with the addition of either $\mathrm{NaOH}$ or $\mathrm{LiOH}$ as a reducing agent and $\mathrm{DMSO}_{2}$, which is an essential material. The EDX spectrum exhibited the presence of the dominant copper $(\mathrm{Cu})$ in 2D copper nanosheets, as indicated by a strong peak of $\mathrm{Cu}$. The FTIR study confirmed the formation of 2D copper nanosheets with $\mathrm{DMSO}_{2}$ by indicating $\mathrm{C}-\mathrm{H}$ bonding. In addition, the UV-Vis spectrum of $2 \mathrm{D}$ copper nanosheets revealed a large peak shift and high absorbance ability. The light absorption peak at $800 \mathrm{~nm}$ indicates that this material has potential applications in laser photonics.

This study was focused on developing a new green synthesis method of 2D copper nanosheets. For future work, structural studies should be conducted, the material properties of 2D copper nanosheets should be evaluated, and the production of 2D copper nanosheets should be realized on a large scale for practical applications.

Author Contributions: Conceptualization, S.L., S.W. and S.Y.; investigation, S.L., S.W., C.W. and S.Y.; methodology, S.L., S.W., C.W. and S.Y.; project administration, S.Y.; writing-original draft, S.L. and S.W.; writing-review and editing, C.W. and S.Y. All authors have read and agreed to the published version of the manuscript.

Funding: This research received no external funding. 
Institutional Review Board Statement: Not applicable.

Informed Consent Statement: Not applicable.

Data Availability Statement: The data presented in this study are available on request from the corresponding author.

Conflicts of Interest: The authors declare no conflict of interest.

\section{References}

1. Bhanushali, S.; Ghosh, P.; Ganesh, A.; Cheng, W. 1D Copper Nanostructures: Progress, Challenges and Opportunities. Small 2015, 11, 1232-1252. [CrossRef]

2. $\quad$ Ling, T.; Wang, J.J.; Zhang, H.; Song, S.T.; Zhou, Y.Z.; Zhao, J.; Du, X.W. Freestanding ultrathin metallic nanosheets: Materials, synthe-sis, and applications. Adv. Mater. 2015, 27, 5396-5402. [CrossRef]

3. Balandin, A.A. Thermal properties of graphene and nanostructured carbon materials. Nat. Mater. 2011, 10, 569-581. [CrossRef]

4. Yu, W.; Xie, H.; Chen, W. Experimental investigation on thermal conductivity of nanofluids containing graphene oxide nanosheets. J. Appl. Phys. 2010, 107, 094317. [CrossRef]

5. Pei, Y.; Huang, L.; Wang, J.; Han, L.; Li, S.; Zhang, S.; Zhang, H. Recent progress in the synthesis and applications of 2D metal nanosheets. Nanotechnology 2019, 30, 222001. [CrossRef] [PubMed]

6. Pawar, S.M.; Pawar, B.S.; Hou, B.; Kim, J.; Ahmed, A.T.A.; Chavan, H.S.; Jo, Y.; Cho, S.; Inamdar, A.I.; Gunjakar, J.L.; et al. Self-assembled two-dimensional copper oxide nanosheet bundles as an efficient oxygen evolution reaction (OER) electrocatalyst for water splitting applications. J. Mater. Chem. A 2017, 5, 12747-12751. [CrossRef]

7. Chaudhari, A.K.; Kim, H.J.; Han, I.; Tan, J.C. Optochemically responsive 2D nanosheets of a 3D metal-organic framework materi-al. Adv. Mater. 2017, 29, 1701463. [CrossRef] [PubMed]

8. Liu, M.; Gurr, P.A.; Fu, Q.; Webley, P.A.; Qiao, G.G. Two-dimensional nanosheet-based gas separation membranes. J. Mater. Chem. A 2018, 6, 23169-23196. [CrossRef]

9. Liu, Z.; Xu, K.; Sun, H.; Yin, S. One-Step Synthesis of Single-Layer MnO2Nanosheets with Multi-Role Sodium Dodecyl Sulfate for High-Performance Pseudocapacitors. Small 2015, 11, 2182-2191. [CrossRef]

10. Li, S.; Chen, J.; Cui, M.; Cai, G.; Wang, J.; Cui, P.; Gong, X.; Lee, P.S. A High-Performance Lithium-Ion Capacitor Based on 2D Nanosheet Materials. Small 2017, 13. [CrossRef]

11. Dubal, D.; Lokhande, C. Significant improvement in the electrochemical performances of nano-nest like amorphous MnO2 electrodes due to Fe doping. Ceram. Int. 2013, 39, 415-423. [CrossRef]

12. Sun, P.; Wang, K.; Zhu, H. Recent developments in graphene-based membranes: Structure, mass-transport mechanism and po-tential applications. Adv. Mater. 2016, 28, 2287-2310. [CrossRef] [PubMed]

13. Dang, R.; Song, L.; Dong, W.; Li, C.; Zhang, X.; Wang, G.; Chen, X.-B. Synthesis and Self-Assembly of Large-Area Cu Nanosheets and Their Application as an Aqueous Conductive Ink on Flexible Electronics. ACS Appl. Mater. Interfaces 2013, 6, 622-629. [CrossRef] [PubMed]

14. Tan, C.; Cao, X.; Wu, X.-J.; He, Q.; Yang, J.; Zhang, X.; Chen, J.; Zhao, W.; Han, S.; Nam, G.-H.; et al. Recent Advances in Ultrathin Two-Dimensional Nanomaterials. Chem. Rev. 2017, 117, 6225-6331. [CrossRef] [PubMed]

15. Yang, F.; Song, P.; Ruan, M.; Xu, W. Recent progress in two-dimensional nanomaterials: Synthesis, engineering, and applications. FlatChem 2019, 18. [CrossRef]

16. Dehghanpour, S.; Mahmoudi, A.; Shadpour, S. Selective synthesis of copper microsheets and ultralong microwires via a surfac-tant assisted hydrothermal process. Russ. J. Gen. Chem. 2015, 85, 1167-1173. [CrossRef]

17. Hou, C.; Zhu, J.; Liu, C.; Wang, X.; Kuang, Q.; Zheng, L. Formaldehyde-assisted synthesis of ultrathin Rh nanosheets for applica-tions in CO oxidation. CrystEngComm 2013, 15, 6127-6130. [CrossRef]

18. Duan, H.; Yan, N.; Yu, R.; Chang, C.-R.; Zhou, G.; Hu, H.-S.; Rong, H.; Niu, Z.; Mao, J.; Asakura, H.; et al. Ultrathin rhodium nanosheets. Nat. Commun. 2014, 5, 3093. [CrossRef]

19. Hu, Y.; Qian, H.; Mei, T.; Guo, J.; White, T. Facile synthesis of magnetic metal (Mn, Co, Fe, and Ni) oxide nanosheets. Mater. Lett. 2010, 64, 1095-1098. [CrossRef]

20. Dubal, D.; Dhawale, D.; Salunkhe, R.; Jamdade, V.; Lokhande, C. Fabrication of copper oxide multilayer nanosheets for supercapacitor application. J. Alloy. Compd. 2010, 492, 26-30. [CrossRef]

21. Shaik, A.H.; Chakraborty, J. A simple room temperature fast reduction technique for preparation of a copper nanosheet pow-der. RSC Adv. 2016, 6, 14952-14957. [CrossRef]

22. Osgood, H.; Devaguptapu, S.V.; Xu, H.; Cho, J.; Wu, G. Transition metal (Fe, Co, Ni, and Mn) oxides for oxygen reduction and evolution bifunctional catalysts in alkaline media. Nano Today 2016, 11, 601-625. [CrossRef]

23. Yin, A.-X.; Liu, W.-C.; Ke, J.; Zhu, W.; Gu, J.; Zhang, Y.-W.; Yan, C.-H. Ru Nanocrystals with Shape-Dependent Surface-Enhanced Raman Spectra and Catalytic Properties: Controlled Synthesis and DFT Calculations. J. Am. Chem. Soc. 2012, 134, 20479-20489. [CrossRef] [PubMed]

24. Roger, I.; Symes, M.D. First row transition metal catalysts for solar-driven water oxidation produced by electrodeposition. $J$. Mater. Chem. A 2016, 4, 6724-6741. [CrossRef] 
25. Lee, J.W.; Han, J.; Lee, D.S.; Bae, S.; Lee, S.H.; Lee, S.K.; Moon, B.J.; Choi, C.J.; Wang, G.; Kim, T.W. 2D Single-Crystalline Copper Nano-plates as a Conductive Filler for Electronic Ink Applications. Small 2018, 14, 1703312. [CrossRef]

26. Liu, X.; Cui, S.; Sun, Z.; Ren, Y.; Zhang, X.; Du, P. Self-supported copper oxide electrocatalyst for water oxidation at low overpoten-tial and confirmation of its robustness by Cu K-edge X-ray absorption spectroscopy. J. Phys. Chem. C 2016, 120, 831-840. [CrossRef]

27. Wang, X.; Tian, W.; Liao, M.; Bando, Y.; Golberg, D. Recent advances in solution-processed inorganic nanofilm photodetectors. Chem. Soc. Rev. 2014, 43, 1400-1422. [CrossRef]

28. Fujioka, N.; Morimoto, Y.; Arai, T.; Kikuchi, M. Discrimination between normal and malignant human gastric tissues by Fourier transform infrared spectroscopy. Cancer Detect. Prev. 2004, 28, 32-36. [CrossRef]

29. Lu, S.; Chen, S.; Zheng, Z.; Zhang, H.; Zhao, C.; Wen, S. Saturable absorption in graphene at 800-nm band. Optoelectron. Devices Integr. IV 2012, 8555, 855512. [CrossRef] 